\title{
A Double-blind, Placebo-controlled, Randomized Comparison of Analgesic Efficacy of Oral Ketorolac Versus Intramuscular Tramadol After Third Molar Surgery
}

Fazil Arshad Nasyam

Department of Oral and Maxillofacial Surgery and Diagnostics Sciences, College of Dentistry, Prince Sattam Bin Abdul Aziz University, Alkarj, SAUDI ARABIA.

\begin{abstract}
Background: Pain due to dental extraction, particularly after the third molar extraction causes discomfort to patients. Different types of analgesics used to manage pain in such cases include nonsteroidal anti-inflammatory drugs and opioids. Objectives: To evaluate the pre-emptive analgesic effectiveness of oral ketorolac and intramuscular (IM) tramadol following lower third molar surgeries. Materials and Methods: A total 60 subjects with impacted mandibular third molars were included in our study. They were randomized into two treatment groups, each with 30 patients. Group A: oral ketorolac $10 \mathrm{mg}$ and IM placebo (1 mL saline solution); Group B: oral placebo (tablet similar to oral ketorolac) and IM tramadol $50 \mathrm{mg}$ diluted in 1 $\mathrm{mL}$ saline solution. The treatment regimen were given half an hour before the start the surgery. The parameters evaluated were pain intensity, the time of first analgesic rescue medication and total analgesic consumption. Results: We found that the time of first rescue analgesic medication was longer in oral ketorolac group than IM tramadol group ( $P=0.01)$. Group $\mathrm{A}$
\end{abstract}

patients experienced less pain than Group B patients. Conclusion: We found that oral ketorolac group of patients had an enhanced analgesic effectiveness and a longer time of first rescue analgesic than those taking intramuscular tramadol.

Key words: Analgesia, Keterolac, Nonsteroidal anti-inflammatory drugs, Tramadol, Third molar.

Correspondence

Fazil Arshad Nasyam,

Assistant Professor, Department of Oral and Maxillofacial Surgery and Diagnostics Sciences, College of Dentistry, Prince Sattam Bin Abdul Aziz University, Alkarj, SAUDI ARABIA.

Email: drfazilpsau@gmail.com

DOI: 10.5330/ijpi.2020.4.102

\section{INTRODUCTION}

One of the common procedures carried in day to day dental practice is dental extraction procedure. This causes pain of moderate to severe and is usually managed with Non-steroidal Anti-inflammatory Drugs (NSAIDs) given for 2-3 days. Impacted third molar extraction causes soft and hard (bone) tissue trauma leading to an acute inflammation with extreme discomfort and pain. ${ }^{1,2}$ Among drugs, NSAIDs have an advantage of being analgesic and anti-inflammatory and are hence the sensible option for treating pain associated with inflammation. ${ }^{3}$

But these drugs cause gastrointestinal adverse effects like gastritis and peptic ulcer and therefore should be used vigilantly. Analgesics like tramadol, which are non-NSAIDs, are used as an alternatives in such patients. ${ }^{4}$

It has been observed that some analgesics if preoperatively administered results in reduction of the onset of postoperative pain. This was supposed to be due to establishment of a suitable blood level of analgesic prior to the surgical injury and also continuation of proper level of analgesic postoperatively. ${ }^{5,6}$

On a whole three categories of analgesics are used to manage pain in such situations NSAIDs, local anesthetics and opioids. Ketorolac is an NSAID that was found effective both orally and parenterally administered. It acts by inhibiting prostaglandins synthesis (fatty acid that causes pain). Apart from this effect this drug has a modulator like action on opioid receptors and stimulates nitric oxide release. Tramadol is an opioid analgesic found to be effective in treating pain of moderate to severe intensity. As it has a low addiction potential, it is used in multiple acute pain conditions, including postsurgical pain. Opiod acts on opioid receptors and modify the transmission of pain, inhibiting the reuptake of serotonin and noradrenaline. ${ }^{7-10}$

Pain due to dental extraction, particularly the third molar extraction, can be considered as a model for acute pain. We carried this study with an aim to evaluate the pre-emptive analgesic efficiency of oral ketorolac compared to intramuscular tramadol after lower third molar surgeries.

\section{MATERIALS AND METHODS}

We carried this randomized, double-blind, placebo-controlled study, following the guidelines of Consolidated Standards of Reporting Trials (CONSORT) group for planning and reporting clinical trials; conducted according to the Declaration of Helsinki and the Ethics Committee approved the study design. ${ }^{11}$

The study was done on 60 subjects with impacted mandibular third molars, after obtaining an institutional ethical committee clearance and informed consent from all the subjects. The study was performed after obtaining institutional ethical committee clearance (PSMMC/ECKAMC:12/2018) and informed consent from all the subjects.

\section{Inclusion criteria}

1. Subjects between 18 to 25 years,

2. Subjects free of systemic disease,

3. Subjects with clinical and radiographic diagnosis of impacted mandibular third molar. 


\section{Exclusion criteria}

1. Use of analgesics $24 \mathrm{hr}$ before the procedure,

2. Subjects with history of seizure disorder, pregnancy or lactation, use of oral contraceptive,

3. Subjects with known hypersensitivity to the study medications.

After explaining the possible risks of oral surgery, the study was carried out. patients They were randomized into 2 groups, each with 30 patients (Figure 1).

Group A: Oral ketorolac $10 \mathrm{mg}$ and IM placebo (1 mL saline solution);

Group B: Oral placebo (tablet similar to oral ketorolac) and IM tramadol $50 \mathrm{mg}$ diluted in $1 \mathrm{~mL}$ saline solution.

The impacted mandibular third molars were classified according to the Winter Classification and Pell and Gregory classification. The difficulty in surgical procedure was categorized on basis of a modified scale of Parant. $^{12}$

1. Grade I, removal with elevators and forceps;

2. Grade II, by osteotomy;

3. Grade III, by osteotomy and coronal section;

4. Grade IV, by osteotomy, root and coronal section.

The treatment regimen were given half an hour before the start the surgery. The parameters evaluated were pain intensity, the time of first analgesic rescue medication and total analgesic consumption. All surgical procedures were done by the same surgeon and evaluations were carried out by an independent investigator. Anesthesia was by nerve block of the lingual, buccal and inferior alveolar nerves by $2 \%$ lidocaine containing 1:100,000 epinephrine. Then the surgery was started.

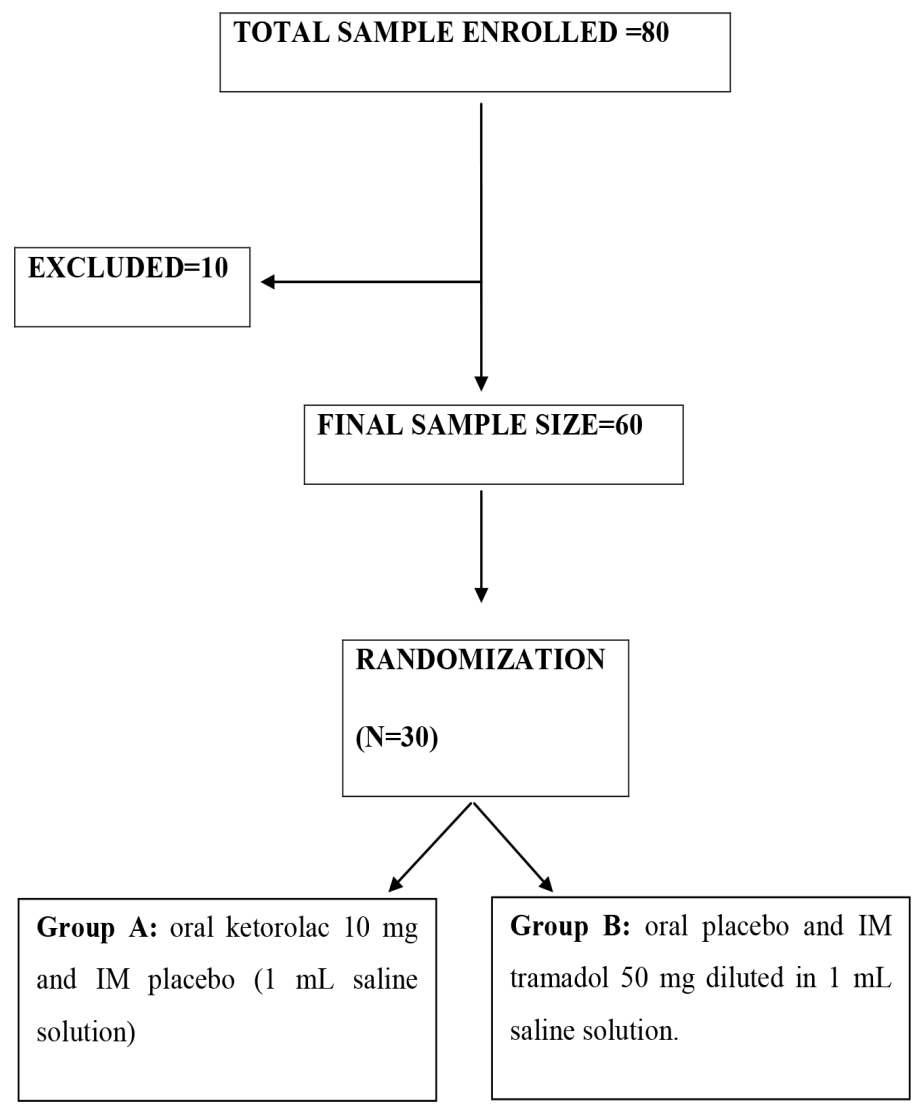

Figure 1: Consort Flow Chart.
The duration of the procedure i.e. from incision to final suture was recorded. A 100-mm visual analog scale (VAS) was employed to gauge pain, 0 , meaning no pain or discomfort and 100, maximum pain or discomfort. VAS was recorded every hour till $8 \mathrm{hr}$ postoperatively and finally $24 \mathrm{hr}$ post-surgery. $10 \mathrm{mg}$ oral ketorolac pills were given and instructed to take one pill for rescue medication 6 hourly apart, accordingly. Total analgesic consumption was evaluated. The analgesic efficacy was based on a three-point categorical scale, 1: poor (severe pain), 2: fair, 3: good (lesspain). Intra and postoperative complications and adverse events were also noted.

Data was recorded as mean and standard deviation, median and ranges or number of frequency and percentage. A P value less than 0.05 was considered significant statistical difference.

\section{RESULTS}

All the demographic and surgical variables were similar among the groups (Table 1).

We found that in oral ketorolac group, the time of first rescue analgesic was longer than in IM tramadol patients. We also found that Group A patients experienced less pain than group $B$ patients, the area under the curve (AUC) of VAS showed statistical difference. Whereas other markers of analgesic efficacy did not illustrate any statistically significant variations among both the groups (Table 2).

Overall, we noticed that Group A patients presented lower pain intensity scores in the third and fourth post-operative hour than Group B patients (Table 3).

Ketorolac group (75\%) showed a good analgesic effect than tramadol group $(25 \%)(P=0.02)$. There was no report of adverse events in any patient.

Table 1: Demographic Profile.

\begin{tabular}{cccc}
\hline Variable & $\begin{array}{c}\text { Group A } \\
(\mathrm{n}=30)\end{array}$ & Group B $(\mathrm{n}=30)$ & P Value \\
\hline $\begin{array}{c}\text { Age in years } \\
\text { (Median and Ranges) }\end{array}$ & $22(18-24)$ & $23(18-25)$ & 0.468 \\
$\begin{array}{c}\text { Gender (Male: Female) } \\
\text { Weight in Kg }\end{array}$ & $21: 9$ & $17: 13$ & 1.04 \\
$\begin{array}{c}\text { (Median and Ranges) } \\
\text { Mesioangular/ }\end{array}$ & $22: 8$ & $64(55-75)$ & 0.762 \\
$\quad$ Horizontal & $18.71)$ & 0.65 \\
$\begin{array}{c}\text { Duration of Operation } \\
\text { (Mean and Ranges) }\end{array}$ & $18.4 \pm 3.1$ & $18.8 \pm 2.9$ & 0.60 \\
$\begin{array}{c}\text { Surgical Difficulty } \\
\text { (Grade II/Grade IV) }\end{array}$ & $11 / 19$ & $14 / 16$ & 1 \\
\hline
\end{tabular}

Table 2: Comparison of the analgesic efficacy.

\begin{tabular}{cccc}
\hline Variable & Group A ( $\boldsymbol{n = 3 0 )}$ & Group B ( $\boldsymbol{n = 3 0 )}$ & P Value \\
\hline $\begin{array}{c}\text { Time of first Rescue } \\
\text { analgesic (Median and } \\
\text { Ranges) }\end{array}$ & $4.6(3.1$ to 8.8$)$ & $3.2(2.8$ to 8.2$)$ & 0.014 \\
$\begin{array}{c}\text { Patients without needing } \\
\text { analgesic during the } \\
\text { period of evaluation (24 } \\
\text { hours) }\end{array}$ & $3(10 \%)$ & $8(26.6 \%)$ & 0.534 \\
$\begin{array}{c}\text { Total analgesic } \\
\text { consumption (Median } \\
\text { and Ranges) }\end{array}$ & $4(0-5)$ & $5(0-6)$ & 0.396 \\
\hline
\end{tabular}


Table 3: Pain intensity Assessment.

\begin{tabular}{cccc}
\hline Hour & Group A $(\boldsymbol{n}=\mathbf{3 0})$ & Group B $(\boldsymbol{n}=\mathbf{3 0})$ & P Value \\
\hline 1 & 1.32 & 11.56 & 0.13 \\
2 & 7.85 & 20.19 & 0.17 \\
3 & 6.59 & 31.32 & 0.015 \\
4 & 12.16 & 33.42 & 0.05 \\
5 & 17.02 & 21 & 0.82 \\
6 & 8.31 & 13.96 & 0.53 \\
7 & 9.86 & 17.62 & 0.34 \\
8 & 8.98 & 25.75 & 0.08 \\
24 & 0.18 & 8.36 & 0.91 \\
\hline
\end{tabular}

\section{DISCUSSION}

Literature search showed that few studies have compared ketorolac and tramadol for relief of pain following oral and maxillofacial surgical procedures like removal of mandibular third molar., ${ }^{1,-15}$

Isiordia-Espinoza MA et al. found that subjects who took oral ketorolac had longer time of analgesic covering and less pain postoperatively than those who received in tramadol. ${ }^{12}$

Gopalraju et al. in their study compared patients who were given $30 \mathrm{mg}$ of ketorolac and $50 \mathrm{mg}$ of tramadol post third molar surgery. They found that ketorolac produced better control of pain. ${ }^{13}$

Mishra et al. in their randomized, double-blind clinical trial noticed that postsurgical administered $100 \mathrm{mg}$ tramadol was as effectual as $20 \mathrm{mg}$ ketorolac in reducing pain. ${ }^{1}$ Whereas Shah et al. ${ }^{14}$ and Ong et al. ${ }^{15}$ observed that ketorolac was better than tramadol for pain management before oral surgery.

Moore et al. observed that ibuprofen and dexketoprofen trometamol resulted in superior analgesia than tramadol following third molar surgery. The probable explanation for enhanced analgesic efficiency of ketorolac than tramadol is the pathogenesis of dental pain, that is largely inflammatory. ${ }^{16}$

Studies showed that NSAIDs have better analgesic effect and at the same time tramadol in higher doses has a enhanced analgesic outcome than ketorolac. Nevertheless, the occurrence of side effects, mainly nausea and vomiting, might be high. Collins et al. in their study on tramadol in reducing dental surgical pain observed more number of patients (39\%) who were on high doses of tramadol (100 mg 4 times per day orally), withdrew from the study than patients on lower doses $(12 \%$ on moderate doses (50 mg 4 times a day) and $6 \%$ on low doses ( $50 \mathrm{mg}$ twice a day) due to side effects like nausea, vomiting and drowsiness. ${ }^{17}$

Pozos-Guillen et al. found similar analgesic effect of $50 \mathrm{mg}$ and $100 \mathrm{mg}$ of tramadol; indicating a partial analgesia outcome of tramadol. ${ }^{18}$ It has been showed that using keterolac preoperatively is unusual due to inhibition of thromboxane A2 and prostaglandin $\mathrm{I} 2$ synthesis, that might cause peri and post-operative bleeding. ${ }^{19}$

Oral surgical procedures usually cause pain and swelling postoperatively and effective analgesia which is safe without any adverse effects is one of the primary requisite. Studies showed that tramadol an opioid drug has good analgesic activity and doesn't cause adverse effects. Nevertheless, systematic reviews and meta-analysis in oral surgery reported that tramadol has lower analgesic efficacy and safety than NSAIDs. One of the commonly used NSAID is ketorolac for managing oral surgery induced pain.

Our primary objective was to evaluate the analgesic effectiveness on reducing pain intensity after removal of impacted molar teeth surgery and occurrence of any the adverse effects with tramadol and ketorolac. Our finding of better analgesic effectiveness of ketorolac when compared to tramadol is mainly ascribed to the pathogenesis of dental surgical pain, that is mainly inflammatory in nature and differs from general surgical pain. The evidence-based medicine has also reported that dental pain is better managed with NSAIDs than opioids. We recommend future studies on a larger sample size to be done to confirm these findings.

\section{CONCLUSION}

We found that patients on 10mg oral ketorolac experienced superior analgesic and a longer time of first rescue analgesic medication than those received $50 \mathrm{mg}$ of im tramadol.

\section{ACKNOWLEDGEMENT}

Department of Oral and Maxillofacial Surgery and Diagnostics Sciences, College of Dentistry, Prince Sattam Bin Abdul Aziz University, Alkarj, SAUDI ARABIA.

\section{CONFLICT OF INTEREST}

The authors declare no conflict of interest.

\section{ABBREVIATIONS}

NSAIDS: Non-steroidal Anti-inflammatory Drugs; CONSORT: Consolidated Standards of Reporting Trials; AUC: Area under the curve; VAS: Visual analog scale.

\section{REFERENCES}

1. Mishra H, Khan FA. A double-blind, placebo-controlled randomized comparison of pre and postoperative administration of ketorolac and tramadol for dental extraction pain. J Anaesthesiol Clin Pharmacol. 2012;28(2):221-5.

2. Khiavi RK, Pourallahverdi M, Pourallahverdi A, Khiavi SG, Oskouei SG, Mokhtari H. Pain control following impacted third molar surgery with bupivacaine irrigation of tooth socket: A prospective study. J Dent Res Dent Clin Dent Prospects. 2010;4(4):105-9

3. Alpaslan C, Alpaslan G, Ugar D. Postoperative pain control by single doses of Piroxicam administered sublingually and aspirin. J Marmara Univ Dent Fac. $1997 ; 2(4): 658-64$

4. Passi D, et al. Comparative Evaluation of Analgesic Efficacy of Oral Ketorolac and Tramadol after Impacted Mandibular Third Molar Surgery: Short Clinical Study with Literature Review. Ann Med Health Sci Res. 2018;8:157-62.

5. Isiordia-Espinoza MA, Pozos-Guillen A, Martinez-Rider R, Perez-Urizar J. Comparison of the analgesic efficacy of oral ketorolac versus intramuscular tramadol after third molar surgery: A parallel, double-blind, randomized, placebocontrolled clinical trial. Med Oral Patol Oral Cir Bucal. 2016;21(5):e637-43.

6. Au AHY, Choi SW, Cheung CW, Leung YY. The Efficacy and clinical safety of various analgesic combinations for post-operative pain after third molar surgery: A systematic review and meta- analysis. PLoS One. 2015;10(6):e0127611.

7. Perez-Urizar J, Martínez-Rider R, Torres-Roque I, Garrocho-Rangel A, PozosGuillen A. Analgesic efficacy of lysine clonixinate plus tramadol versus tramadol in multiple doses following impacted third molar surgery. Int J Oral Maxillofac Surg. 2014;43(3):348-54.

8. Lee SY, Lee WH, Lee EH, Han KC, Ko YK. The effects of paracetamol, ketorolac and paracetamol plus morphine on pain control after thyroidectomy. Korean $\mathrm{J}$ Pain. 2010;23(2):124-30.

9. Grant GM, Mehlisch DR. Intranasal ketorolac for pain secondary to third molar impaction surgery: A randomized, double-blind, placebo-controlled trial. J Oral Maxillofac Surg. 2010;68(5):1025-31.

10. Vazzana M, Andreani T, Fangueiro J, Faggio C, Silva C, Santini A, et al. Tramadol hydrochloride: pharmacokinetics, pharmacodynamics, adverse side effects, co-administration of drugs and new drug delivery systems. Biomed Pharmacother. 2015;70:234-8.

11. Altman DG, Schulz KF, Moher D, Egger M, Davidoff F, Elbourne D. The revised CONSORT statement for reporting randomized trials: Explanation and elaboration. Ann Intern Med. 2001;134(8):663-94.

12. Isiordia-Espinoza MA, Sánchez-Prieto M, Tobías-Azúa $F$, Reyes-García JG Preemptive analgesic effectiveness of meloxicam versus tramadol after third molar surgery: A pilot clinical study. J Oral Maxillofac Surg. 2012;70(1):31-6.

13. Gopalraju P, Lalitha RM, Prasad K, Ranganath K. Comparative study of intravenous tramadol versus ketorolac for preventing postoperative pain after 
third molar surgery-a prospective randomized study. J Craniomaxillofac Surg. 2014;42(5):629-33.

14. Shah AV, Arun KKV, Rai KK, Rajesh KBP. Comparative evaluation of pre-emptive analgesic efficacy of intramuscular ketorolac versus tramadol following third molar surgery. J Maxillofac Oral Surg. 2013;12(2):197-202.

15. Ong KS, Tan JML. Preoperative intravenous tramadol versus ketorolac for preventing postoperative pain after third molar surgery. Int J Oral Maxillofac Surg. 2004;33(3):274-8.

16. Moore RA, Gay-Escoda C, Figueiredo R, Tóth-Bagi Z, Dietrich T, Milleri S. Dexketoprofen/tramadol: Randomised double-blind trial and confirmation of empirical theory of combination analgesics in acute pain. J Headache Pain. 2015;16(1):541.

17. Collins M, Young I, Sweeney P, Fenn GC, Stratford ME, Wilson A. The effect of tramadol on dento-alveolar surgical pain. Br J Oral Maxillofac Surg. 1997;35(1):548.

18. Pozos-Guillen A, Martinez-Rider R, Aguirre-Bañuelos P, Pérez-Urizar J. Pre-emptive analgesic effect of tramadol after mandibular third molar extraction: A pilot study. J Oral Maxillofac Surg. 2007;65(7):1315-20.

19. Schafer Al. Effects of nonsteroidal antiinflammatory drugs on platelet function and systemic hemostasis. J Clin Pharmacol. 1995;35(3):209-19.

Article History: Submission Date : 05-09-2019; Revised Date : 30-11-2019; Acceptance Date : 25-01-2020.

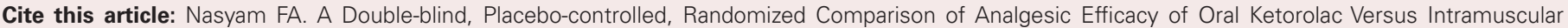
Tramadol After Third Molar Surgery. Int. J. Pharm. Investigation. 2020;10(4):586-9. 